\title{
Features
}

\section{Approaches to Biology Teaching and Learning: Lesson Study-Building Communities of Learning Among Educators}

\author{
Deborah Allen, ${ }^{*+}$ Richard Donham, ${ }^{\ddagger}$ and Kimberly Tanner ${ }^{\S}$
}

\author{
*Department of Biological Sciences, University of Delaware, Newark, Delaware 19716; $¥$ Mathematics \& Science \\ Education Resource Center, University of Delaware, Newark, Delaware 19716; and §University of California at \\ San Francisco, Science and Health Education Partnership, San Francisco, California 94143-0905
}

\begin{abstract}
I learned that planning a science lesson as a group can be very frustrating as well as very rewarding: Frustrating when I had to suspend certain beliefs that I held about what constitutes a good science lesson in order to really listen to what another member of our group was trying to share.... Rewarding in having the chance to think deeply about what I think is important in planning, assessing, and delivering a lesson, and getting to hear what other people think is important.
\end{abstract}

-A teacher participating in a San Francisco Lesson Study group

For $>20 \mathrm{yr}$, the American public has grown accustomed to the drumbeat of bad news about their schools. Poor performance on standardized tests, gaps in achievement between minority and white students, and high student drop-out rates have become part of the modern lexicon. It is clear that the path forward to address these problems should emphasize and reflect the overwhelming importance of effective teaching. There is cogent evidence that a competent teacher, with good quality curricular materials and adequate resources, makes a major difference in student performance on standardized evaluations (Ferguson, 1991; Hammond and Ball, 1997; Wenglinski, 2000). This fact was recognized by the National Commission on Mathematics and Science Teaching for the 21st Century when it stated that, "...the most direct route to improving mathematics and science achievement for all students is better mathematics and science teaching" (U.S. Department of Education, 2000, p.7).

Beyond the gloomy numbers in international examinations, which show that students in the United States do poorly in both science and mathematics when compared with students in comparable countries, there is perhaps a silver lining. Researchers are looking closely at the educational cultures of consistently high-performing countries, such as Japan, and asking if there are similarities and differences in approaches, and what aspects of those systems are transferable to our own.

What they are finding is perhaps surprising. There are dramatic differences in the methods used by teachers in Ja-

DOI: $10.1187 / \mathrm{cbe} .03-12-0028$

${ }^{+}$Corresponding author. E-mail address: deallen@udel.edu. pan and their counterparts in the United States. Examination of many hours of videotapes (as part of the Third International Mathematics and Science Study [TIMSS] videotape study project) (Stigler et al., 1999) of mathematics teaching suggests that teachers in the United States are more likely to state concepts directly to students, while teachers in Japan predominantly develop students' thinking about concepts rather than simply stating the concepts. Teachers in Japan (Stigler and Hiebert, 1999) focus more of their lesson content on what is referred to as "medium or high quality mathematical content" (such as problem-solving strategies), whereas U.S. teachers spend most of their lesson time occupied with "low quality content" (such as repetitive practice). In Japan, a high percentage of lessons include student presentations, whereas in the United States, $<10 \%$ of 8 th-grade lessons involve student presentations. It appears from analysis of Japanese and U.S. educational systems that the difference is not so much in the teacher competence as in the methods that the teachers use.

One might argue that teachers transfer to their classroom many of the practices and methods that were used by their teachers. Whether or not that is the case, Japanese school systems, particularly at the elementary grade levels, incorporate a mechanism for helping in-service teachers to incrementally improve their classroom practice. Known as Lesson Study (or jugyou kenkyuu in Japan), it is a mechanism that helps Japanese teachers to improve their practice based on evidence from the classroom. Lesson Study is based on a long-term, continuous improvement model-one that values gradual change built on existing classroom practice. It starts from the premise that the lesson-that is, what happens in the classroom-is critically important. The purpose of Lesson Study is not to produce the "perfect lesson," but rather to catalyze the process of professional development that occurs when teachers collaboratively reflect on student understanding and the evidence for it, and plan the classroom experience. It is focused on student learning and on the classroom observations, evidences, and student work that reveal the level of success. It is a collaborative process, allowing teachers to engage in a mutually supportive deconstruction of what went right as well as what went 
wrong during a lesson, building on shared ownership of the product lesson. It moves teachers into the realm of researchers, using the classroom as their laboratory-a place where they hypothesize, test, evaluate, and revise in much the same way that bench scientists do.

Although college- and university-level science educators are not faced with the climate of standardized test-driven, high stakes accountability that many $\mathrm{K}-12$ educators sense that they operate in, they are nevertheless being confronted with powerful encouragement to rethink the way they have been teaching science to undergraduate students (National Research Council, 2003a,b). Although not yet practiced extensively at the college and university level, the process of Lesson Study offers a model for how faculty could accomplish this revisioning of undergraduate science education through a series of collaborative, gradual and continual improvements in classroom practice, rather than through the more daunting process of wholesale, dramatic change. The Lesson Study process also provides multiple opportunities for partnerships across the K-16 continuum, because the broad goals for student learning of science across the continuum are often the same.

\section{THE LESSON STUDY CYCLE}

Although Lesson Study is most pervasive in the elementary schools of Japan, it is not unique to any country, and its essential features are embraced by teachers everywhere. What is studied or is the subject of research in Lesson Study is the actual classroom lesson. However, what makes this approach different from typical classroom practice is that the lessons become much more than the concern of individual teachers working in isolation-in Lesson Study, small groups of teachers meet on a regular basis to collaborate on the planning, implementation, evaluation, and subsequent revision of classroom lessons (Stigler and Hiebert, 1999).

Lesson Study as it is practiced in Japan can take place within just one school (single school Lesson Study) or can be open to teachers and educators from a broader region, such as a local school district (public Lesson Study). It can even take place among participants at a regional or national conference. The frequency of Lesson Study group meetings can vary from several times a year to a more intensive schedule of meeting once a month or even once a week. Catharine Lewis and Ineko Tsuchida (1998) and Makoto Yoshida (1999), on the basis of their extensive observations of Japanese classrooms, have described what are now generally considered to be the major elements of the Lesson Study cycle. These elements are explained briefly in the paragraphs below and are summarized in Figure 1.

\section{Goal Setting}

Lesson Study begins with the setting of shared, long term goals for improvement that connect with desired student characteristics. These goals are broadly stated so that they can serve to motivate and unify the process, and in addition to remind teacher participants of the qualities that may underlie student learning, but that often get forgotten in the routine of daily classroom practice. When setting the goals for Lesson Study, teachers might think about the biggest gap between what they perceive as students' actual qualities and those that are ideal. Some examples of these broadly stated goals include "to develop instruction that ensures that students achieve basic academic abilities while fostering their individuality," "for students eyes to light up when learning science," or "for students to become problem-solvers" (Lewis, 2002a). The Lesson Study group then translates these broadly stated goals into the context of a particular grade level or subject matter theme.

\section{Collaborative Lesson Selection and Planning}

A next step is for the group to identify and choose a unit of study, and then to hone in on a specific lesson topic. The chosen unit and topic are aligned with the both overarching goals and the more specific grade or subject matter goals (Lewis, 2002b; Research for Better Schools, 2003). Members of the Lesson Study group then meet regularly to collaborate on the planning of a particular lesson and how it will be taught. During this phase of lesson selection, teachers may do independent research and report back to the group as a whole on their findings, turning to their own prior instruction, textbooks, and Web sites for sources of the best available materials to inform the lesson-selection process. It is also during this phase that Lesson Study group members might invite an outside expert (a so-called knowledgeable other) to help enhance content knowledge about the subject matter, discuss ideas about how students think and learn, or otherwise support the planning of the research lesson (Research for Better Schools, 2003).

\section{Teaching the Lesson with Peer Observation}

After agreement is reached about the best strategies for the lesson and its instruction, one of the teachers who participated in the planning teaches it to an actual class. Any one of the teachers that participated in the planning of the lesson might do the teaching. What is different about Lesson Study is that the teaching is observed by fellow teachers in the Lesson Study group, along with the knowledgeable other(s) and is often videotaped. The observers collect data on student learning and thinking, often working in a predetermined way - for example, different observers may focus on different aspects of what is transpiring in the class. The task of one observer might be to record the methods that students use to problem solve, while another might focus on collecting and recording information on student interest and motivation (Lewis, 2002c). In Japan, the study lessons are sometimes observed by teachers from other schools, even teachers traveling from other regions of the country. Although the teacher delivering the lesson at these "Open House" observations may feel some trepidation, this is minimized because the lesson is collaboratively planned, and because the other members of the planning team share the responsibility for the lesson. In addition, the focus of the observation process is on the lesson, not on the teacher.

\section{Debriefing the Lesson}

Following the Lesson Study, participants meet to debrief the lesson. This research colloquium typically begins with the teacher who taught the lesson speaking first about his or her perceptions of what went well or went poorly. The other members of the Lesson Study group then explain the goals 


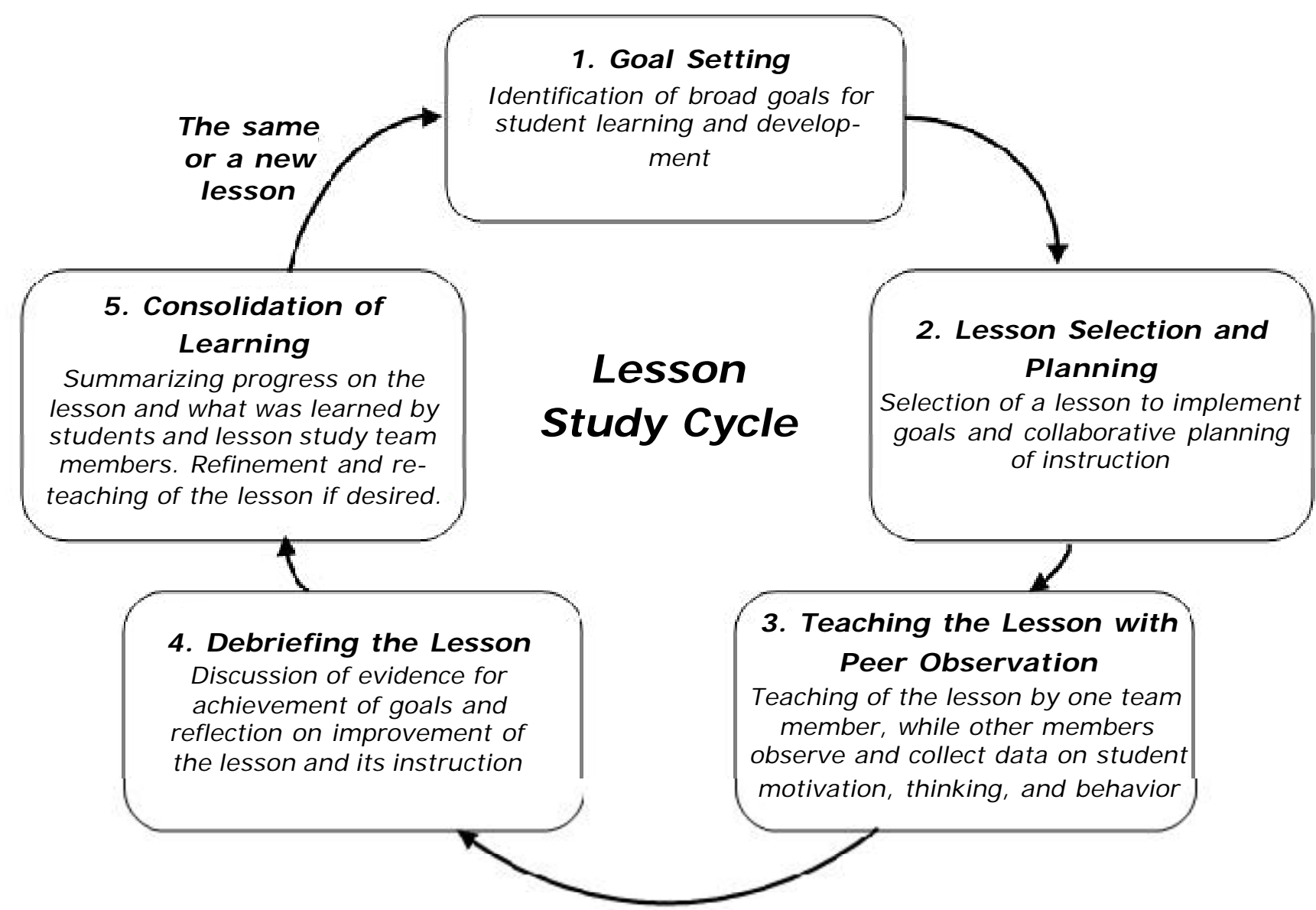

Figure 1. Elements of Lesson Study, an educator-driven professional development cycle. The ultimate purpose of Lesson Study is not to achieve a perfect lesson, but rather for participants to experience together the process of thinking deeply about specific ways to achieve major instructional goals and of how to determine if these goals have been achieved. Modified from Lewis, Catharine, C., Lesson Study: A Handbook of Teacher-Led Instructional Change, $2002 \mathrm{~b}, \mathrm{p} .3$.

for the lesson and how it was designed to accomplish them. The entire group of observers, including any invitees if the lesson has been an "Open House," then discusses the evidence gathered during the lesson, using either a structured or more open-ended format. Observers report on what students did during the lesson, on evidence of student learning, and on the level of students' engagement, persistence, and/or frustration. The discussions are often lively, since the lessons by their design are provocative, evoking the often different perspectives that individuals hold about how children learn and develop (Lewis, 2002a).

\section{Consolidation of Learning}

The information from this research discussion is used by the study group to continue to improve the lesson. The lesson is often retaught by a new teacher after incorporation of the revisions. The cycle of goal setting, collaboration on planning and revision, peer observation of teaching, and informed fine tuning continues, culminating in a product lesson. Working in this manner, a Lesson Study group may re- tain the same research theme for several years, or begin the cycle again with a new theme.

\section{LESSON STUDY IN THE UNITED STATES}

In an article that served as many educators' introduction to Lesson Study in the United States, Lewis and Tsuchida (1998) raised concerns about whether Lesson Study was transferable to this country. Some of what they viewed as the important supporting conditions for Lesson Study may be absent in the United States. For instance, Japan has a national curriculum, described as "spare" or "frugal" because it covers far fewer subject matter topics at each grade level than does the typical U.S. curriculum. As a result, more class periods can be devoted to each topic, and teachers can spend more time exploring effective ways to teach it. Collaboration among teachers that often cuts across schools and even regions is the norm in Japan, despite the fact that the daily time that teachers spend with students is as least as much as in the United States. This continuous, collective effort is con- 
sidered essential to achievement of good teaching. Finally, self-critical reflection as a path to improvement, a core premise of Lesson Study, is an established and esteemed practice in Japanese culture; at the same time teachers are much less subject to external evaluation by the school administration, and the climate for revealing one's weaknesses may thus be a safer one. In the absence of these supporting contexts in the United States, Lewis and Tsuchida have voiced concern that the central premises of Lesson Study might be diluted by "domestication" to fit the prevailing circumstances of a given Lesson Study group.

Despite these concerns, since 1999, numerous Lesson Study projects have sprung up in the United States as teachers and administrators recognize that it incorporates the idea that teachers should be leaders in their own professional development. The first Lesson Study Open House in the United States was held at Paterson Public School Number 2 in a high poverty area of Paterson, $\mathrm{NJ}$, in collaboration with the Greenwich Japanese School of Connecticut, the Lesson Study Research Group of Teachers College of Columbia University, and Research for Better Schools (Fernandez and Yoshida, 2001). Other school groups soon followed suit. An example of such a group is offered below to illustrate how Lesson Study can unfold in the U.S. context.

One example of a lesson-study-inspired effort comes from the University of California at San Francisco's Science and Health Education Partnership (UCSF SEP), a partnership between the university and the local public schools to support K-12 science education. As a follow-up opportunity to a UCSF SEP graduate-level summer course in biology, elementary, and middle school teacher alumni of the course are invited to join an SEP Teaching Roundtable. These Teaching Roundtables are intended to support classroom implementation of ideas learned in the course and engage teachers in sharing lessons, analyzing student work, and reflecting on teaching challenges. Each Teaching Roundtable generally involves three to six teachers from multiple schools and across multiple grade levels. In early versions of the Round tables, discussions of design of science assessments, adaptation of curriculum materials to be more inquiry-based, and student participation and development were often limited in depth by a lack of a common experience of a particular lesson by the group.

To address this issue, an SEP Teaching Round table group in its second year chose to adopt a Lesson Study approach so that they could together, as a group, plan, teach, assess, reflect upon, and redesign one science lesson in depth. The five teachers in this SEP Teaching Roundtable included two 3 rd-grade, one 5th-grade, one 8th-grade, and one $\mathrm{K}-5 \mathrm{Sci}-$ ence Resource teacher, representing one middle and four elementary schools. The group embarked upon an effort where all of the teachers would collaborate on planning a science lesson that could be taught across grades 3, 5, and 8. After much analysis and discussion of the California State Science Standards, the group decided that the content focus of the lesson would be on the chemical properties of matter, a content strand that appears at each of these grade levels. As in traditional Lesson Study efforts, the group invested a substantial amount of discussion time in negotiating the goals for student learning that would guide the overall development of the lesson. It was decided that the lesson should provide opportunities for students to: (1) understand that substances can be identified through differences in their physical and chemical properties, (2) develop skills and attitudes of problem solvers, and (3) have the courage to test their own ideas.

After six planning meetings, the collaboratively developed a Mystery Powders Challenge lesson series, based on the Elementary Science Study (ESS) Unit entitled Mystery Powders (ESS, undated). The lesson series was taught in one 8th-, one 5th-, and two 3rd-grade classrooms. Each incarnation of the lesson was observed by at least one other group member and often times several, and videotaped by an SEP staff member. Observing group members collected evidence from a pair of students, taking detailed field notes of student conversations that would later be transcribed, shared, and used to reflect on the lesson. After teaching the Mystery Powders Challenge lesson in these four classrooms at three grade levels, individual teachers watched videos of their classroom and wrote written reflections on what they learned in planning and teaching the lesson. Subsequently, the group reconvened to exchange observations, classroom field notes, and insights, as well as to discuss classroom evidence of how well the lesson, as currently designed, helped students make progress towards achieving the original lesson goals. In final, written reflections, teachers described their own learning as a result of the Lesson Study-inspired experience, as presented in Table 1.

As we hope is clear from this example, the practice of Lesson Study can have an important impact. It can improve teachers' morale through a lessening of their sense of isolation as they assume shared ownership of important goals and practices of their profession. It gives teachers an oppor-

Table 1. Quotes excerpted from the final written reflections of elementary and middle school educators who participated in a Lesson Study project (as part of a Science and Health Education Partnership Teaching Roundtable)

\begin{tabular}{cc}
\hline Quote & Educator \\
\hline
\end{tabular}

I have never worked this closely and extensively planning one lesson with a group of teachers. I have learned that I like working together much more than I imagined, and actually learn more with reflection time.

I was surprised by how much third graders were able to perform and analyze the lab-if I were to just look at their written work without observing the class, I may not have come to this conclusion; however, the students' conversations showed that they understood more than they were able to express in the written form.

I relished the opportunity to observe others' classrooms and see tremendous benefit in taking detailed observational notes and sharing them with other teachers.

I think that I would not have been exposed to so many different ideas about science teaching and learning had I only been talking with my own colleagues from one work environment or with teachers from only one grade level. It was the variation in our backgrounds, daily practice, and perspectives that made the conversations interesting.
Educator A

Educator $\mathrm{H}$

Educator $\mathrm{X}$
Educator M 


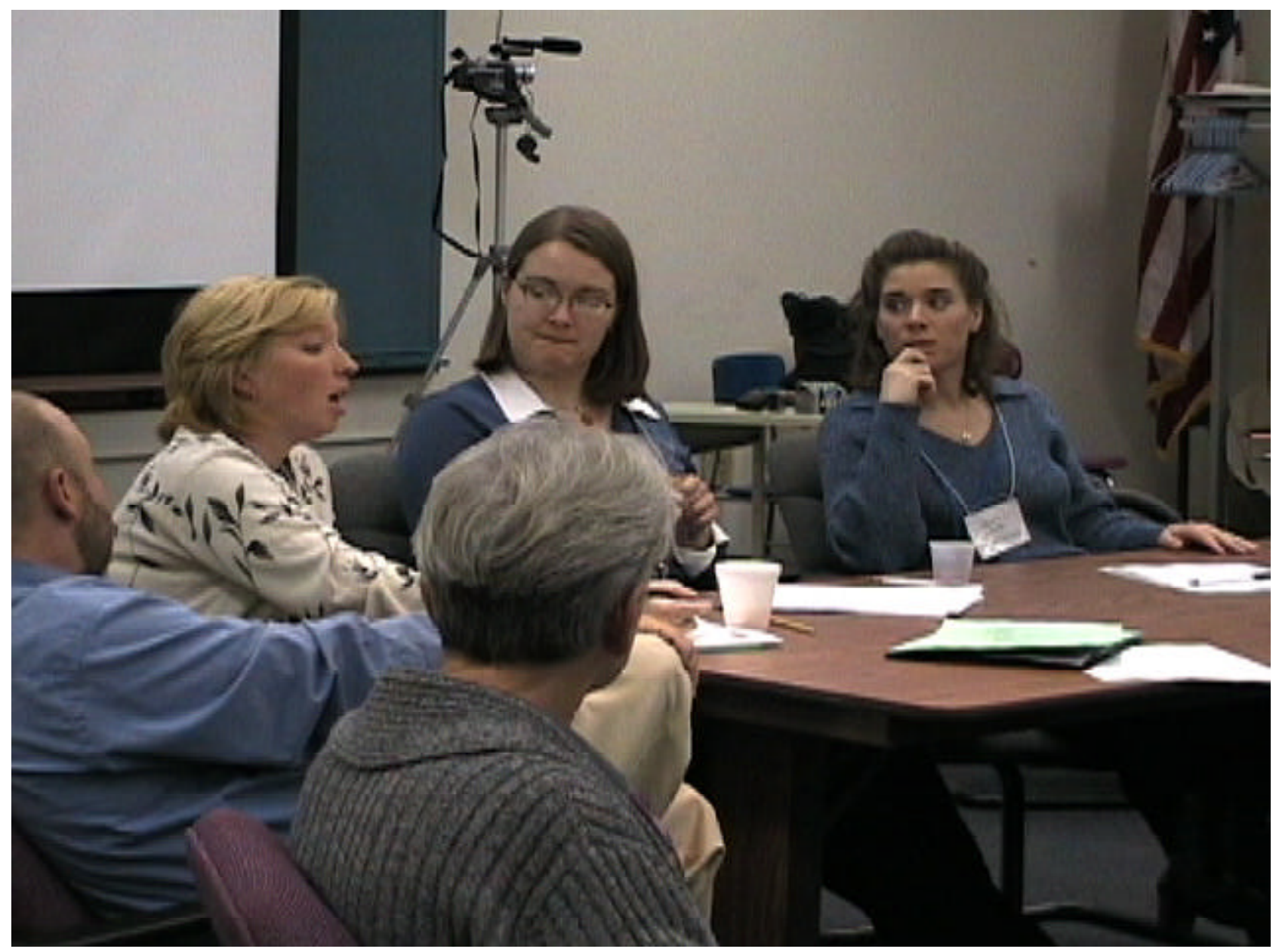

Figure 2. Lesson Study group composed of middle school teachers, administrators and univ ersity faculty.

tunity to carefully study student learning and behavior, see their teaching through the eyes of both colleagues and students, and as a result, to develop powerful instructional knowledge that can be applied to their teaching of any lesson (Lewis, 2002c).

\section{COLLEGE AND UNIVERSITY PARTNERS IN LESSON STUDY}

Lesson Study provides an opportunity for partnerships between the $\mathrm{K}-12$ community and higher education that can benefit both sides of the collaboration. The first Lesson Study at Paterson Public School Number 2 (Fernandez and Yoshida, 2001) provides an example of such partnership, as do the longstanding collaboration between Mills College (where Catharine Lewis is on the faculty) and regional California schools (Mills College, undated), and the SEP Teaching Round table described above. Another example of such a partnership started in Delaware in the fall of 2002, when teachers and administrators and university faculty began a Lesson Study project to incorporate this approach into the culture of middle school science teaching within Brandywine and Christina School Districts (Figure 2). With approxi- mately thirty 7th- and 8th-grade teachers and their administrators involved, this project is now in its third Lesson Study cycle. Over the past year, members of the Lesson Study group have met numerous times in all-day and after school workshops (planning sessions), have had two Lesson Study Open Houses, where they opened the doors to the public (including the School Board and district-level administrators), and have traveled to out-of-state Lesson Study Open House demonstrations. One of the research lessons from this collaboration focused on the difficult conceptual topic of levels of organization of living systems; another research lesson focused on connecting the characteristics of phase change with data that students collected supporting the particle model.

More important than the observable features of Lesson Study has been a gradual deepening of the level of professionalism on the part of teachers. Discussions are focusing on the important details of classroom practice. Teachers are incorporating evidence from student work in their discussions. Teachers are growing as leaders in their schools by identifying barriers such as the lack of time in the school day for collaboration focused on instruction, and are communicating their needs to their administrators. They are also 
becoming leaders within the project, and the project is moving steadily toward the time when Lesson Study will be sustainable by the teachers themselves. The teachers feel that, because of their efforts, student achievement will gradually improve.

What role might the university and its faculty have within this system of school-based, teacher-led professional development? In the case of this Delaware Lesson Study, the project was initiated by University faculty who obtained a Title II (No Child Left Behind) award. This award provides funding for many of the activities of the project. During the grant-writing phase, there were discussions with administrators and teachers to incorporate their thinking and to recruit Teacher-Leaders within the two districts. These grant funds have supported travel to Open Houses in New Jersey and Connecticut, have provided substitute teachers where needed, and have provided organizational support for many of the activities during the first year. Video equipment has been purchased so that teachers can collect a record of the lessons to be used for reflective discussions. Finally, the faculty have facilitated the Lesson Study discussions and sometimes served as the "knowledgeable others" by providing content expertise. During the first year, many of the activities were initiated by the faculty, but the project will soon be less dependent on faculty and more "owned" by the teachers.

\section{A FUTURE FOR LESSON STUDY IN COLLEGES AND UNIVERSITIES?}

Lesson Study addresses many of the concerns about the effectiveness of science teaching at the college and university level expressed by the National Research Council (2003b). What would it take to add the formal structures of Lesson Study to what is typically now a less focused enterprise, one in which the overarching educational goals of the institution, the department, the course itself may get lost in the everyday mechanics of running a large enrollment course? Multisectioned, introductory courses might be fertile ground for attempting to collaboratively introduce reflective discussions about classroom practice, based on evidence from faculty classroom observations of student performance. The instructional staff of these courses often includes graduate and /or undergraduate teaching assistants; introduction of lesson study to this setting would have the added benefit of providing opportunities for the professional development of these nascent educators.

A test of this idea will occur in the spring of 2004 at the University of Delaware. In the spring semester of 2003, two of us (D.A. and R.D.), in collaboration with faculty and administrations from the Physics, Biology and Geology Departments and the School of Education, joined together all of the basic science courses that elementary education majors take plus science teaching methods into a single entity called the "Science Semester." This course, which allocated 4-credit hours to each of the discipline areas (physical, life, earth science and teaching methods), used strategies such as problem-based learning to foster integrated understandings of science across disciplines. While the course was in session, the faculty and teaching assistants met regularly to debrief each week's classes; all faculty were generally present at both the course meetings and the debriefings. Our goals were to provide students with a more integrated understanding of science and how it can powerfully inform and enrich their understanding of the world, and to help them along the road toward becoming reflective teachers.

In this Science Semester enterprise, we are clearly on a trajectory that could lead to Lesson Study. It seems a small, but somehow intimidating, step to add the other components: structured peer observations, videotaping and recording of data focused on student understandings, reflections on student performance, reflective discussions focused on the lesson, not the teacher. Is this an idea with real potential to launch us on a path to achieving more effective teaching and learning? Or will we fall victim to Lewis' and Tsuchida's concerns (1998) about Lesson Study projects that fail to operate in the context achieved in the Japanese cultural triad of a "shared and frugal" curriculum, emphasis on collaboration, and esteem for critical self-reflection? We look forward to finding out.

\section{ACKNOWLEDGMENTS}

We wish to thank the teachers participating in the UCSF SEP'S Teaching Roundtable for sharing the insights from their final written reflections. Some of the work described above was supported by a grant from DOE (Title II, No Child Left Behind) to R.D. and colleagues, and by a grant from the Howard Hughes Biomedical Research Institute to K.T. and colleagues.

\section{REFERENCES}

Elementary Science Study. Mystery Powders: Teacher's Guide. Hudson, NH: Delta Education. Ordering information for the guide and Mystery Powders kit is available at http://cf.synergylearning.org/ DisplayResource.cfm? selectedresource $=183$.

Ferguson, R.F. (1991). Paying for public education: new evidence on how and why money matters. Harvard J. Legisl. 28, 465.

Fernandez, C., and Yoshida, M. (2001). Lesson Study as a model for improving teaching: insights, challenges, and a vision for the future. In: Eye of the Storm: Promising Practices for Improving Instruction. Findings from the 2000 Wingspread Conference. Washington, DC: Council for Better Education. Available online at http://www.c-be.org PDF/EyeoftheStormFernandez.pdf.

Hammond, L.D., and Ball, D. L. (1997). Teaching for High Standards: What Policymakers Need to Know and Be Able to Do; National Education Goals Panel. Available at http://www.negp.gov Reports/ highstnds.htm.

Mills College. Lesson Study Group at Mills College. Available at http://www.lessonresearch.net.

Lewis, C.C., and Tsuchida, I. (1998). A lesson is like a swiftly flowing river: how research lessons improve Japanese education. Am. Educ. Winter, 14-17; 50-52. Available at http://www.lessonresearch.net/ lesson.pdf.

Lewis, C.C. (2002a). Does Lesson Study Have a Future in the United States? Nagoya J. Educ. Hum. Dev. 1, 1-23. Available at http:// www.lessonresearch.net/res.html.

Lewis, C.C. (2002b). Lesson Study: A Handbook of Teacher-Led Instructional Change. Philadelphia, PA: Research for Better Schools.

Lewis, C.C. (2002c). What are the essential elements of Lesson Study? Calif. Sci. Proj. Connect. 2, (No.1) November/December, 1, 4. Available at http://www.lessonresearch.net/newsletter11_2002.pdf.

National Research Council (2003a). Bio2010: Transforming Undergraduate Education for Future Research Biologists. Committee on Undergraduate Biology Education to Prepare 
Research Scientists for the 21st Century. Washington, DC: National Academies Press. Available at http://www.nap.edu/books/ 0309085357 html.

National Research Council (2003b). Improving Undergraduate Instruction in Science. Technology, Engineering, and Mathematics: Report of a Workshop. Committee on Undergraduate Science Education. Washington, DC: National Academies Press. Available at http://www.nap.edu/books /0309089298/html.

Research for Better Schools (2002). What is Lesson Study? Currents 5, (No. 2), 1-2. Available at http://www.rbs.org/currents/0502/ index.shtml.

Stigler, J. W., Gonzales, P., Kawanaka, T., Knoll, S., and Serrano, A. (1999). The TIMSS Videotape Classroom Study: Methods and Findings from an Exploratory Research Project on Eighth Grade Mathematics Instruction in Germany, Japan and the United States. Washington, DC: National Center for Education Statistics.
Stigler, J. W., and Hiebert, J. (1999). The Teaching Gap: Best Ideas from the World's Teachers for Improving Education in the Classroom. New York: Free Press.

U.S. Department of Education (2000). Before It's Too Late: A Report to the Nation from the National Commission on Mathematics and Science Teaching for the 21st Century. Washington, DC: Education Publication Center. Available at http://www.ed.gov/americacounts / glenn.

Wenglinski, H. (2000). How Teaching Matters: Bringing the Classroom Back Into Discussions of Teacher Quality. Princeton, NJ: Educational Testing Service and The Millken Family Foundation. Available at http://www.ets.org/research/pic.

Yoshida, M. (1999). Lesson Study: A Case Study of a Japanese Approach to Improving Instruction Through School-Based Teacher Development. Ph.D. thesis. Chicago: University of Chicago. 